\title{
Long-Term Outcome of Patients With Functional Dyspepsia Infected With A Cag-Positive Helicobacter Pylori Strain. A Descriptive Study.
}

\author{
L Kemps and RJLF Loffeld* \\ Department of Internal Medicine, Zaans Medisch Centrum Zaandam, The Netherlands
}

Received: February 1, 2017; Accepted: March 25, 2017; Published: April 17, 2017

*Corresponding author: RJLF Loffeld, Department of Internal Medicine, Zaans Medisch Centrum, PO BOX 210, 1500 EE Zaandam, The Netherlands, Tel: (0)75-6502779; Fax: (0)75-6502379; E-mail: loffeld.r@zaansmc.nl

\begin{abstract}
Introduction: An important virulence factor of H.pylori is the Cagpathogenicity island. The clinical sequel in patients with functional dyspepsia treated for H.pylori on the long-term is not known.

Aim: Establish long-term outcome and relate this to the initial H.pylori status (CagA- positive or negative).

Patients and Methods: In 1994/1995 a study on presence of H.pylori was done. IgG antibodies against cagA were determined. Three groups of patients were made: group 1: H.pylori + and CagA+; group 2: H.pylori + and CagA-; and group 3: H.pylori -patients. An extensive chart review and several questionnaires were used (a general questionnaire, the GerdQ, theSAI, and, the GSRS). Use of acid suppressive drugs was assessed.
\end{abstract}

Results: 411 patients were included. New upper GI-endoscopies were significantly more often done in patients of group $1(\mathrm{p}<0.001)$. Reflux disease was significantly more often diagnosed in group 1 patients $(\mathrm{p}=0.02)$. After exclusions 239 patients $(58.2 \%)$ received the questionnaires, 101 respondents were evaluable. Patients in group 1 reported significantly more often complaints. There was no significant difference in the overall presentation when patients of group 1 were compared with patients of group 2. However, there was a significant difference between the scores in H.pylori+ patients when compared with patients of group 3. Patients of group 1 significantly used more often acid suppressive therapy.

Conclusion: functional dyspeptics with H.pylori CagA+strain, may develop more often complaints in the future necessitating a new endoscopic investigations. Signs of reflux disease are more often present.

Key-words: Dyspepsia; H.pylori; Cag-A; Follow-up; Upper Gastrointestinal Endoscopy

\section{Introduction}

The description of Helicobacter pylori was a major breakthrough in Gastroenterology in the past decennia. The bacterium causes ulcer disease and distal gastric cancer. Since the establishment of the anti-Helicobacter treatment prevalence of peptic ulcer disease, once a chronic problem, dramatically decreased. Despite many studies, there still is discussion on the necessity of eradicating the microorganism in patients with functional dyspepsia. Zhao et al did a meta-analysis on the longterm effects of therapy in patients with functional dyspepsia and concluded that this therapy is associated with consistent improvement of dyspeptic symptoms [1]. The number needed to treat to cure one case of dyspepsia is fourteen according to a large meta-analysis of the Cochrane institute [2].

An important virulence factor of H.pylori is the so-called Cag-pathogenicity island, containing the cytotoxin associated gene (cagA). The product of this gene is the immunodominant antigen CagA [3,4]. Patients with H.pylori positive ulcer disease are almost invariably cagA-positive [5,6]. Patients with CagA positivity also have an increased risk of gastric cancer [7].

Obviously, nowadays, all patients diagnosed with H.pylori infection are treated with anti-Helicobacter therapy. It is not known what the clinical sequelis in functional dyspeptics treated for H.pylori positive gastritis on the long-term. Most studies have a follow-up of six months till one year [1]. Another important point is the hypothesis that H.pylori might be protective against the development of gastroesophageal reflux disease [8].

A study was done in order to establish long-term out come in the sense of upper abdominal complaints, reflux complaints, and consultations for upper gastrointestinal complaints and relate this to the initial H.pylori status (CagApositive or negative).

\section{Patients and Methods}

In 1994/1995 a study on presence of H.pylori in all consecutive patients sent to the Endoscopy Department of the Zaans Medisch Centrum, the community Hospital of the Zaanstreek region in the Netherlands, was performed [9]. Endoscopy was done with EVIS-100 Video endoscopes from Olympus (Olympus Nederland BV Zoeterwoude).

In the present study only patients in whom no macroscopic abnormalities were seen during the endoscopy were included. These patients were diagnosed with functional dyspepsia (non-ulcer dyspepsia). During the procedure biopsy 
specimens were taken from the gastric antrum for haematoxilin/ eosin and immunoperoxidase stain $(\mathrm{n}=2)$, rapid urease test $(\mathrm{n}=1)$, and Gram stain with culture $(\mathrm{n}=1)$ according to previously described methods [10]. A patient was considered H.pyloripositive if one or more of the detection methods was positive. A patient was H.pylori-negative if all methods were negative. A serum sample was taken and frozen at minus 70 degrees Celsius. Specific IgG antibodies against the H.pylori cagA were determined as described earlier $[9,11]$.

For the present follow-up study, the dyspeptic patients were grouped in three groups. Group 1:H.pylori positive and CagA positive; Group 2: H.pylori positive and CagA negative; and finally Group 3: patients negative for H.pylori.

Part of the patients diagnosed with functional dyspepsia participated in a trial with so-called reversed randomisation [12]. These patients were treated with the combination of omeprazole and amoxicillin. The trial did not include standard biopsies after completion of the study. Non-participants in this study were treated with the classic triple therapy or the classic quadruple therapy with bismuth, amoxicilline, metronidazole and protonpump inhibition. The majority of patients did not undergo follow-up endoscopy after treatment. The present study consists of two parts: first a chart review of all patients, and, second, the application of a number of questionnaires sent to all patients still alive at the date of evaluation.

\section{Chart review}

An extensive chart review was done of all hospital records and endoscopy reports from all patients in order to obtain data on consultations, new endoscopies, and abnormalities related to oesophagus, stomach or duodenum. In other words a period of more than 20 years was covered. If patients still visited their community hospital, it was assumed that they also would have been sent for new upper gastrointestinal endoscopy to the open-access department or to the out-patient clinics for consultation in case of upper abdominal complaints. In addition, the national registry of pathology was searched for presence of histological examinations in oesophagus or stomach from the patients done in other hospitals.

\section{Questionnaires}

In December 2015, all patients still alive received an extensive questionnaire by mail. Patients not capable of reading the Dutch language were excluded. The questionnaire was already used and validated in previous studies [13,14]. The questionnaire was composed of four different lists of questions pertaining to upper abdominal complaints.

A general questionnaire consisted of 20 questions $[13,14]$. The first question in the general questionnaire was: "Do you experience any upper abdominal complaint?" Severity and frequency of complaints were scored on a five and six point Likert scale respectively. Severity was scored as: 0 none; 1 light; 2: moderate; 3: serious; 4: serious complaint interfering with daily life. The minimum overall mean score for severity was 1 , the maximum score 40 . Severity score was calculated per patient. The overall mean frequency was scored as: 6: several times a day; 5: once daily; 4: several times a week; 3: once a week; 2: several times a month; 1 : once a month. The minimum score on frequency was 1 , the maximum score 60 .

The GerdQ is a validated questionnaire that reveals a scoring on reflux symptomatology on the 7 days prior to receiving the list [15]. It calculates the probability that a patient has gastrointestinal reflux disease using six questions.

The SAI (symptom activity scale), which is a modified functional bowel disorder severity index, takes into account a subjective evaluation of the patients complaints, whether or not they have been present for over 6 months (chronic complaints) and how many times a patient consulted a general practitioner because of these complaints. A score of 36 or lower indicates mild complaints, a score between 37 and 110 is consistent with average complaints and a score of 111 or higher indicates severe complaints $[16,17]$. The gastrointestinal symptom rating scale (GSRS) ranges from 0 points when a patient has no complaints up to 18 points when a patient has all of six specified symptoms on a regular basis [18]. Use of acid suppressive drugs was assessed with the questions whether or not a patient used acid suppressive therapy. Statistical analysis was done with chi-square test for contingency tables and t-test. A value below 0.05 was considered statistical significant.

\section{Results}

\section{Chart review}

In total 411 patients were included. Table 1 shows the characteristics in the three groups. There was no difference in men or women. Mean age was 49 years (standard deviation 16 , range 15-86) in group 1; 53 years (SD 18,range 23-83) in group 2; and 45 (SD 17.5, range 12-67) in group 3. Patients in group 2 were significantly older $(\mathrm{p}<0.001)$, although significant overlap is present. Hence, as to be expected, more patients in group 2 had died by the time of the evaluation. New upper GIendoscopies were significantly more often done in patients of group $1(p<0.001)$. But if new endoscopies were done, there was no difference in the number of new endoscopies in the individual patients in the three groups in the entire follow-up period (Table 1).

Only a minority of the patients in group 1 were not in the hospital system anymore, implying that they either moved out of the region or never went for any consultation again. This number was significantly higher in groups 2 and $3(\mathrm{p}=0.03)$. Table 2 shows the yield of the new endoscopies in the three groups of patients. In follow-up, reflux disease was significantly more often diagnosed in patients of group $1(\mathrm{p}=0.02)$. If biopsies were obtained during the endoscopy, these mostly were negative for H.pylori, indicating successful prior treatment. In all groups ulcers were detected.

The main reason was use of NSAID's. Stomach cancer 
Table 1: The characteristics of the three groups of patients (The number between brackets is the percentage). Group 1: H.pylori positive and CagA positive; Group 2: H.pylori positive and CagA negative; and Group 3: patients negative for H.pylori

\begin{tabular}{|c|c|c|c|c|}
\hline & Group 1 & Group 2 & \multicolumn{2}{|c|}{ Group 3} \\
\hline Number & 130 & 91 & 190 & \\
\hline Men & $51(60.7)$ & $42(46.2)$ & $78(40)$ & \\
\hline Women & $79(53.8)$ & $49(53.8)$ & $112(58.9)$ & $\mathrm{P}=\mathrm{ns}$ \\
\hline $\begin{array}{l}\text { Not in the hospital } \\
\text { system anymore }\end{array}$ & $12(9.3)$ & $20(21.9)$ & $31(16.3)$ & \\
\hline Deceased & $29(22.3)$ & $34(38)$ & $36(19)$ & \\
\hline $\begin{array}{l}\text { No consultations in } \\
2015\end{array}$ & $89(68.4)$ & $37(40.1)$ & $123(64.7)$ & \\
\hline $\begin{array}{l}\text { No pre-mortal } \\
\text { consultations }\end{array}$ & 12 & 12 & 14 & \\
\hline New endoscopy & $72(55)$ & $37(41)$ & $57(30)$ & $\begin{array}{c}\mathrm{P}< \\
0.001\end{array}$ \\
\hline
\end{tabular}

Number of new endoscopies

\begin{tabular}{|c|c|c|c|}
\hline 1 & $33(45.8)$ & $20(54)$ & $35(61.4)$ \\
\cline { 1 - 3 } & $17(23.6)$ & $8(21.6)$ & $10(17.5)$ \\
\cline { 1 - 3 } & $12(16.6)$ & $4(10.8)$ & $7(12.3)$ \\
\hline$>3$ & $10(14)$ & $5(13.6)$ & $2(8.8)$ \\
\hline
\end{tabular}

Table 2: Yield of the new endoscopy (The number between brackets is the percentage). Group 1: H.pylori positive and CagA positive; Group 2: H.pylori positive and CagA negative; and Group 3: patients negative for H.pylori. Signs of reflux disease $=$ presence of typical reflux complaints with or without oesophagitis or hiatal hernia.

\begin{tabular}{|c|c|c|c|}
\hline & Group 1 & Group 2 & Group 3 \\
\hline No abnormalities & $59(82)$ & $24(65)$ & $38(67)$ \\
\hline $\begin{array}{c}\text { Signs of reflux } \\
\text { disease }\end{array}$ & $11(15)$ & $6(16)$ & $14(25)$ \\
\hline Ulcer & $1(15)$ & $6(16)$ & $4(7)$ \\
\hline Unknown & - & - & $1(1)$ \\
\hline H.pylori positive & 1 & 2 & - \\
\hline H.pylori negative & 25 & 3 & 14 \\
\hline
\end{tabular}

diagnosis of functional dyspepsia. Oesophageal cancer was seen in one patient of group 2 already one year after the initial study.

\section{Questionnaires}

Of the 411 patients, 172 were excluded because they had either died or were not able to read or understand the Dutch language. Two hundred and thirty nine patients of the initial group (58.2\%) received the questionnaires. Of these 131 $(54.8 \%)$ responded. Of these 5 additional patients had died, 13 returned the questionnaires without answering to the questions, and 12 moved to another address. Finally 101 respondents were evaluable.

Patients in group 1 reported significantly more often complaints compared with those in groups 2 and 3 (Table 3).

Table 3: Overall presence or absence of upper abdominal complaints scored by the questionnaire, the Gerd-Q, the SAI or the GSRS in the three groups of patients (the number between brackets is the percentage). Group $1=\mathrm{Hp}+\mathrm{Cag}+$, Group $2=\mathrm{Hp}+\mathrm{Cag}-$, Group $3=\mathrm{Hp}-$

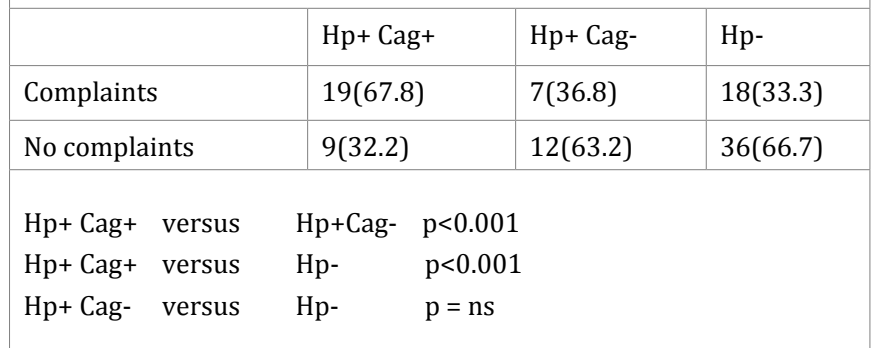

There was no significant difference in the scores of the general questionnaire, the GerdQ the SAI, and the GSRS when patients of group 1 were compared with patients of group 2 . However, there was a significant difference between the scores in H.pylori-positive patients when compared with patients of group 3. Table 4 shows the results of the general questionnaire, the frequency score of complaints, the GerdQ SAI, and GSRS in the three groups of patients.

Table 5 shows the use of acid suppressive therapy in the three groups of patients. As can be seen the patients who were H.pylori+ and CagA+ used significantly more often acid suppression when compared with the other two groups.

\section{Discussion}

Ever since H.pylori was described and its role in ulcer disease and gastritis was established, a link between H.pylori colonisation and dyspepsia has been sought [19-21]. There is definitely a link between the clinical presentation and the virulence status of H.pylori [9].

The present study shows follow-up of more than 20 years in patients with functional dyspepsia especially related to H.pylori status. The majority of patients still visited their community hospital for all kinds of reasons. Some are treated in the out patients clinics of Internal Medicine or Gastroenterology, many visit other departments. Patients show great loyalty towards their community hospital. Hence, it can be assumed that if a patient had upper abdominal complaints, he/she again will visit his/her hospital and will undergo endoscopy if the general practitioner or the medical specialist feels the procedure is 
indicated.

Table 4: Results of the general questionnaire, the frequency score of complaints, the GerdQ, SAI, and GSRS in the three groups of patients. Group $1=\mathrm{Hp}+\mathrm{Cag}+$, Group $2=\mathrm{Hp}+\mathrm{Cag}-$, Group 3 = Hp.

\begin{tabular}{|c|c|c|c|c|c|}
\hline & $\begin{array}{c}\text { General } \\
\text { questionnaire }\end{array}$ & Frequency & GerdQ & SAI & GSRS \\
\hline \multicolumn{6}{|c|}{$\mathrm{Hp}+\mathrm{Cag}+$} \\
\hline Mean & 10.37 & 20.68 & 6.05 & 36.53 & 6.58 \\
\hline SD & 6.21 & 13.23 & 4.39 & 32.25 & 2.78 \\
\hline Median & 9 & 17 & 5 & 42 & 7 \\
\hline Range & $3-26$ & $3-53$ & $0-14$ & $0-101$ & $1-10$ \\
\hline \multicolumn{6}{|c|}{$\mathrm{Hp}+\mathrm{Cag}-$} \\
\hline Mean & 13.67 & 27.67 & 7.17 & 45.17 & 7.33 \\
\hline SD & 7.79 & 14.38 & 3.76 & 29.4 & 3.72 \\
\hline Median & 10 & 23.5 & 7 & 53.5 & 7.5 \\
\hline Range & $6-24$ & $10-50$ & $2-13$ & $5-72$ & $3-11$ \\
\hline \multicolumn{6}{|c|}{ Hр- } \\
\hline Mean & 6.72 & 12.06 & 2.67 & 18 & 4.33 \\
\hline SD & 4.79 & 9.4 & 2.25 & 19.67 & 2.85 \\
\hline Median & 7 & 13 & 0.53 & 21.9 & 0.67 \\
\hline Range & $0-19$ & $0-39$ & $0-7$ & $0-54$ & $0-12$ \\
\hline
\end{tabular}

\begin{tabular}{|c|c|}
\hline $\mathrm{Hp}+\mathrm{Cag}+$ versus $\mathrm{Hp}+\mathrm{Cag}-$ & $\mathrm{p}=\mathrm{ns}$ \\
\hline $\mathrm{Hp}+\mathrm{Cag}+$ versus Hp- & $p=0.05$ \\
\hline Hp+ Cag- versus Hp- & $\mathrm{p}=0.01$ \\
\hline \multicolumn{2}{|c|}{ Frequency } \\
\hline $\mathrm{Hp}+\mathrm{Cag}+$ versus $\mathrm{Hp}+\mathrm{Cag}-$ & $\mathrm{p}=\mathrm{ns}$ \\
\hline $\mathrm{Hp}+\mathrm{Cag}+$ versus Hp- & $\mathrm{p}=0.02$ \\
\hline $\mathrm{Hp}+$ Cag- versus Hp- & $\mathrm{p}=0.00$ \\
\hline \multicolumn{2}{|c|}{ GerdQ } \\
\hline $\mathrm{Hp}+\mathrm{Cag}+$ versus $\mathrm{Hp}+\mathrm{Cag}-$ & $\mathrm{p}=\mathrm{ns}$ \\
\hline $\mathrm{Hp}+\mathrm{Cag}+$ versus Hp- & $\mathrm{p}=0.07$ \\
\hline $\mathrm{Hp}+\mathrm{Cag}-$ versus Hp- & $\mathrm{p}=0.03$ \\
\hline \multicolumn{2}{|c|}{ SAI } \\
\hline $\mathrm{Hp}+\mathrm{Cag}+$ versus $\mathrm{Hp}+\mathrm{Cag}-$ & $\mathrm{p}=\mathrm{ns}$ \\
\hline $\mathrm{Hp}+\mathrm{Cag}+$ versus Hp- & $p=0.04$ \\
\hline $\mathrm{Hp}+$ Cag- versus Hp- & $p=0.03$ \\
\hline \multicolumn{2}{|c|}{ GSRS } \\
\hline $\mathrm{Hp}+\mathrm{Cag}+$ versus Hp+ Cag- & $\mathrm{p}=\mathrm{ns}$ \\
\hline $\mathrm{Hp}+\mathrm{Cag}+$ versus Hp- & $p=0.02$ \\
\hline $\mathrm{Hp}+$ Cag- versus Hp- & $\mathrm{p}=0.05$ \\
\hline
\end{tabular}

Table 5: Use of medication (acid suppressive therapy) in the three groups of patients at time of the evaluation. $+=$ positive for medication use or complaints, - = negative. The number between brackets is the percentage. Group $1=\mathrm{Hp}+\mathrm{Cag}+$, group 2 = Hp+Cag-, group $3=\mathrm{Hp}-$

\begin{tabular}{|c|c|c|c|}
\hline & Hp+ Cag+ & Hp+ Cag- & Hp- \\
\hline Medication+/complaints+ & 16 & 5 & 13 \\
\hline Medication+/complaints- & 4 & 2 & 5 \\
\hline \multicolumn{4}{|l}{} \\
\hline Medication -/complaints + & 3 & 2 & 5 \\
\hline Medication -/complaints - & 5 & 10 & 31 \\
\hline \multicolumn{4}{|c|}{} \\
\hline Total & \multicolumn{4}{|l}{} \\
\hline Medication + & 20(71.4) & $7(36.8)$ & $18(33.3)$ \\
\hline Medication - & $8(28.6)$ & $12(63.2)$ & $36(66.7)$ \\
\hline
\end{tabular}

\begin{tabular}{|l|l|}
\hline Hp+Cag+ versus Hp+Cag- & $\mathrm{p}=0.04$ \\
\hline $\mathrm{Hp}+$ Cag+ versus Hp- & $\mathrm{p}=0.001$ \\
\hline $\mathrm{Hp}+$ Cag- versus Hp- & $\mathrm{p}=\mathrm{ns}$ \\
\hline
\end{tabular}

Data are missing in this study. Patients, who were dead at time of the evaluation, obviously cannot respond to the questionnaires anymore. It is also normal that a number of patients are non-responders. On the other hand, given the long follow-up, the number of actually responding patients could be called rather high. Despite these missing data, in our opinion, conclusions can be drawn.

An important finding in the present study is the fact that patients initially diagnosed with an H.pylori Cag-positive strain reported significantly more often that they still experienced upper abdominal complaints when compared with the Cagnegative strains or the H.pylori-negative patients. However, on the long-term patients who was H.pylori negative experienced significantly less often complaints or had a lower score in the different questionnaires. Harvey et al. studied the long-term effect of Helicobacter eradication. After 2 years, a 35\% reduction in consultations for dyspepsia occurred. An extension of this study showed an ongoing trent in reduction of consultations in the next 2 and 7 years [22]. In another study it was shown that only $36 \%$ of functional dyspeptics were without any complaint seven years after treatment with anti-Helicobacter treatment [23]. Hansen et al. studied a very large population of individuals screened for presence of H.pylori after five years of follow-up. The response rate in Hansen's study was very high, 94\%. A modest effect on dyspepsia, and a modest, but significant effect on the consultation rate and sick leave days for dyspepsia were noted [24]. 
Another finding in the present study, although largely as indirect evidence, is the fact that patients who initially were infected with CagA-positive bacteria had the highest number of new endoscopies in the years to follow. Implicating more consultations because of complaints. Also these patients had a higher prevalence of reflux disease.

Also the fact that higher number patients in groups 2 and 3 were not in active the hospital system anymore is indirect evidence that they did rather well after being treated for their dyspepsia. Of course, it is always possible that they were referred to another hospital. But on the other hand why would a larger percentage of patients from group 1 still visit their hospital?

Patients received different anti-Helicobacter treatments. Triple therapy or even quadruple therapy is the most effective. However, anti-Helicobacter dual therapy with high dose proton pump inhibition can be as effective [25]. In the initial study biopsy specimens after therapy were not done routinely. But, if a patient underwent a new endoscopic investigation, biopsy specimens were often taken and proved to be H.pylori- negative in many cases implying successful prior anti-Helicobacter therapy (Table 2).

On the long-term the prognosis of functional dyspepsia is rather fair. The scores in the general questionnaire are lower than reported in a previous study in patients with active disease [22]. It can be concluded that patients with functional dyspepsia and H.pylori gastritise infected with a more virulentH.pylori strain (this is CagA-positive), may develop more often complaints in the future necessitating a new endoscopic investigations and treatment. Signs of reflux disease are more often present. H.pylori possibly seems to be protective against development of reflux disease [8].

\section{References}

1. Zhao B, Zhao J, Cheng WF, Shi WJ, Liu W, Pan XL, et al. Efficacy of Helicobacter pylori eradication therapy on functional dyspepsia: a meta-analysis of randomized controlled studies with 12-month follow-up. J Clin Gastroenterol. 2014;48(3):241-247. doi: 10.1097/ MCG.0b013e31829f2e25

2. Moayyedi P, Soo S, Deeks J, Delaney B, Harris A, Innes M, et al. Eradication of Helicobacter pylori for non-ulcer dyspepsia. Cochrane Database Syst Rev. 2006;19(2):CD002096.

3. Covacci A, Lange N, Censini S. The cag pathogenicity island of Helicobacter pylori. In: Hunt RH, Tytgat GNJ eds, Helicobacter pylori Basic mechanism to clinical cure. Kluwer Dordrecht. 1996:40-49.

4. Censini S, Lange C, Xiang ZY, Crabtree JF, Ghiara P, Borodovsky, et al. Cag, a pathogenicity island of Helicobacter pylori encodes type I-specific and disease associated virulence factors. Proc Natl Acad Sci. 1996;93(25):14648-14653.

5. Weel JF, van der Hulst RWM, Gerrits Y, Roorda P, Feller M, Dankert J, et al. The interrelationship between cytotoxin associated gene-A and vacuolating cytotoxin and Helicobacter pylori related diseases. J Infect Dis. 1996;173(5):1171-1175.

6. Crabtree JE, Taylor JD, Wyatt Jl, Heatley RV, Shalcross TM, Tomkins DS, et al. Mucosal IgA recognition of Helicobacter pylori $120 \mathrm{kDa}$ protein, peptic ulceration, and gastric pathology. Lancet. 1991;338(8763):332-
335.

7. Matos JI, de Sousa HA, Marcos-Pinto R, Dinis-Ribeiro M. Helicobacter pylori CagA and VacA genotypes and gastric phenotype: a metaanalysis. Eur J Gastroenterol Hepatol. 2013;25(12):1431-1441. doi: 10.1097/MEG.0b013e328364b53e

8. Loffeld RJ, van der Hulst RW. Helicobacter pylori and gastrooesophageal reflux disease: association and clinical implications. To treat or not to treat with anti-H. pylori therapy? Scand J Gastroenterol Suppl. 2002;236:15-18.

9. Loffeld RJ, Werdmuller BF, Kusters JG, Kuipers EJ. Functional dyspepsia is associated with cagA-positive Helicobacter pylori strains. Scand J Gastroenterol. 2001;36(4):351-355.

10.Loffeld RJLF, Stobberingh E, Arends JW. A review of diagnostic techniques for diagnosing Helicobacter pylori infection. Digestive Diseases. 1993;11(3):173-180.

11. Pena AS, Endtz HPH, Offerhaus GJ, Hoogenboom-Verdegaal A, van Duijn W, de Vargas N, et al. Value of serology (ELISA and immunoblotting) for the diagnosis of Campylobacter pylori infection. Digestion. 1989;44(3):131-141.

12. Werdmuller BF, van der Putten AB, Veenendaal RA, Lamers CB, Balk AG, Loffeld RJ. Functional dyspepsia has a good prognosis irrespective of $\mathrm{H}$. pylori status. Long-term follow-up of symptoms after anti $\mathrm{H}$. pylori treatment. Neth J Med. 1999;55(2):64-70.

13. Dackus GH, Loffeld SM, Loffeld RJ. Use of acid suppressive therapy more than 10 years after the endoscopic diagnosis of reflux esophagitis with specific emphasis to trademark and generic proton pump inhibitors. J Gastroenterol Hepatol. 2012;27(2):368-371. doi: 10.1111/j.14401746.2011.06855.x

14. Loffeld SM, Dackus GM, Loffeld RJ. The long-term follow-up of patients with endoscopically diagnosed reflux oesophagitis with specific emphasis to complaints. Eur J Gastroenterol Hepatol. 2011;23(12):1122-1126. doi: 10.1097/MEG.0b013e32834b8d18

15. Jones R, Junghard O, Dent J, Vakil N, Halling K, Wernersson B, et al. Development of the GerdQ a tool for the diagnosis and management of gastro-esophageal reflux disease in primary care. Aliment Pharmacol Ther. 2009;30(10):1030-1038. doi: 10.1111/j.13652036.2009.04142.x

16.Drossman DA. Do psychosocial factors define symptom severity and patient status in irritable bowel syndrome? Am J Med. 1999;107(5A):41-50.

17. Drossman DA, Li Z, Toner BB, Diamant NE, Creed FH, Thompson D, et al. Functional bowel disorders. A multicenter comparison of health statusand development of illness severity index. Dig Dis Sci. 1995;40(5):986-995.

18. Kulich KR, Madisch A, Pacini F, Piqué JM, Regula J, Van Rensburg CJ, et al. Health Qual Life Outcomes. 2008;6:12. doi:10.1186/1477-7525-612

19. Tally JN, Janssens J, Lauritzen K, Racz I, Bolling-Sternevald E. Eradication of Helicobacter pylori in functional dyspepsia: randomised double blind placebo controlled trial with 12 months' follow-up. BMJ. 1999;318(7187):833-837.

20. Talley NJ, Vakil N, Ballard ED, Fennerty MB. Absence of benefit of eradicating Helicobacter pylori in patients with nonulcer dyspepsia. N Engl J Med. 1999;341:1106-1111.

21.Werdmuller BFM, van der Putten ABMM, Veenendaal RA, Lamers CBHW, Balk AG, Loffeld RJLF. Functional dyspepsia has a good prognosis irrespective of H.pylori status. Neth J Med. 1999;55(2):64- 
70.

22. Werdmuller BFM, van der Putten ABMM, Loffeld RJLF. The presentation of reflux oesophagitis, hiatal hernia, Barrett's oesophagus and "refluxlike" dyspepsia: a prospective clinical and endoscopical study. Dis of the Esophagus. 1996;9:285-289.

23. Harvey RF, Lane JA, Nair P, Egger M, Harvey I, Donovan J, et al. Clinical trial: prolonged beneficial effect of Helicobacter pylori eradication on dyspepsia consultations - the Bristol Helicobacter Project. Aliment Pharmacol Ther. 2010;32(3):394-400. doi: 10.1111/j.13652036.2010.04363.x

24. Maconi G, Sainaghi M, Molteni M, Bosani M, Gallus S, Ricci G, et al Predictors of long-term outcome of functional dyspepsia and duodenal ulcer after successful Helicobacter pylori eradication--a 7-year followup study. Eur J Gastroenterol Hepatol. 2009;21(4):387-393.

25. Hansen JM, Wildner-Christensen M, Hallas J, Schaffalitzky de Muckadell OB. Effect of a community screening for Helicobacter pylori: a 5-Yr follow-up study. Am J Gastroenterol. 2008;103(5):1106-1113. doi: 10.1111/j.1572-0241.2007.01770.x

26.Ince AT, Tozlu M, Baysal B, Şentürk H, Arıcı S, Özden A. Yields of dual therapy containing high-dose proton pump inhibitor in eradication of $\mathrm{H}$. pylori positive dyspeptic patients. Hepatogastroenterology. 2014;61(133):1454-1458 